\title{
Electrospinning scale-up and formulation development of PVA nanofibers aiming oral delivery of biopharmaceuticals
}

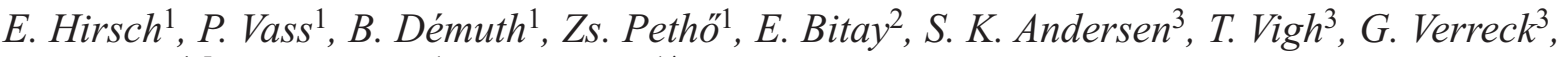 \\ K. Molnár ${ }^{4,5}$, Zs. K. Nagy ${ }^{1}$, Gy. Marosi ${ }^{1 *}$ \\ ${ }^{1}$ Department of Organic Chemistry and Technology, Faculty of Chemical Technology and Biotechnology, Budapest \\ University of Technology and Economics, H-1111, Budapest, Müegyetem rakpart 3, Hungary \\ ${ }^{2}$ Faculty of Technical and Human Sciences, Sapientia Hungarian University of Transylvania, 540485 Târgu-Mureş, \\ Op. 9., Cp. 4., Romania \\ ${ }^{3}$ Oral Solids Development, Janssen R\&D, B-2340 Beerse, Turnhoutseweg 30, Belgium \\ ${ }^{4}$ Department of Polymer Engineering, Faculty of Mechanical Engineering, Budapest University of Technology and \\ Economics, H-1111, Budapest, Müegyetem rakpart 3, Hungary \\ ${ }^{5}$ MTA-BME Research Group for Composite Science and Technology, Müegyetem rakpart 3, H-1111 Budapest, Hungary
}

Received 5 December 2018; accepted in revised form 4 February 2019

\begin{abstract}
Electrospinning is a promising drying technology providing a rapid and gentle drying at ambient temperature, thus electrospinning of polyvinyl alcohol aqueous solutions was investigated for the solid formulation of biopharmaceuticals. The commonly used single-needle electrospinning does not have adequate productivity to satisfy the industrial requirements, therefore our aim was to study the scale-up of the technology by using high-speed electrospinning. High molecular weight polyethylene oxide as a secondary polymer was applied to enhance the fiber formation of polyvinyl alcohol. While polyvinyl alcohol-polyethylene oxide formulations resulted in adequate fiber formation it was not possible to process them further as the friability of the fibers was too low. In order to increase the friability, the effect of adding various sugars (mannitol, glucose, lactose, saccharose, and trehalose) was investigated. The results showed that mannitol was the best friability enhancing excipient because of its crystallinity and low moisture content in the fibrous sample. In contrast, glucose, lactose, saccharose, and trehalose were amorphous with higher moisture content and fibers containing these were grindable only after post-drying.
\end{abstract}

Keywords: nanomaterials, electrospinning, scale-up, biopharmaceuticals, oral formulation

\section{Introduction}

The application of biopharmaceuticals for oral administration is a topic of great interest in the pharmaceutical industry due to the inherent advantages of oral delivery [1]. Biopharmaceutical formulations are more stable in the solid state than in liquid form; in addition, it has many advantages like storage at ambient temperature, longer shelf-life, easier product shipping and the possibility of controlled drug delivery [2]. Currently, the pharmaceutical industry is typically applying freeze drying and spray drying processes in order to obtain solid biopharmaceuticals, however, both technologies have disadvantages $[3,4]$. Freeze drying is a time-consuming batch technology, has high energy consumption, and the freezing can cause degradation of the biomolecules. On the contrary, spray drying can be operated continuously, is more economical, but can induce inactivation of heat-sensitive molecules, due to the high drying temperature. Electrospinning (ES), which is originally a fiber drawing technology, can be a promising alternative for continuous drying technologies, providing

${ }^{*}$ Corresponding author, e-mail: gmarosi@mail.bme.hu C BME-PT 
a rapid and gentle drying at ambient temperature [57]. Thus, ES technology can be applied for the solid formulation of various biopharmaceuticals such as enzymes, peptides, proteins, monoclonal antibodies, oligonucleotides and live cells [8-11]. As both freeze and spray drying can induce degradation of biopharmaceuticals, they are typically formulated with various excipients to preserve the activity, amongst which the most commonly used excipients are sugars (like mannitol, saccharose, and trehalose being the typical choices) $[5,12,13]$. The exact protection mechanism is not known, but there are two hypotheses (namely the vitrification and water replacement hypotheses), that explain the protective effect of sugars on the active pharmaceutical ingredient (API) stability $[14,15]$.

Considering the sensitivity of biopharmaceuticals the use of aqueous solutions during electrospinning is strongly preferred. This preference makes the development more challenging, from the productivity point of view. Owing to the high boiling point of aqueous solutions compared to the volatile organic solvents, the productivity of the method is reduced. Using the conventional laboratory-scale ES equipment, single-needle electrospinning (SNES) with aqueous solutions, only $0.5-1.0 \mathrm{ml} / \mathrm{h}$ feeding rate was achieved up to now [16-18].

SNES equipment does not have adequate productivity, thus in order to satisfy the industrial requirements, the scale-up of ES is necessary. Different methods have been created to scale up the process and there are equipments commercially available on the market [19]. The most commonly used technique is multineedle ES, which has a well-known drawback that is related to the alteration of the electric field profile induced by the presence of other electrospinning jets nearby $[20,21]$. The other technique used for the scale-up of the electrospinning process is the needleless 'free-surface' ES [22]. From the free-surface of the polymer solution, several jets can be created, however evaporation of the solvent results in the change of solution composition and viscosity. High-speed electrospinning (HSES) technique seems to be a promising way to meet the pharmaceutical requirements of the scale-up [23]. The fiber formation process, accelerated by electrostatic and centrifugal forces, allows mass production of nanofibers, while the concentration of the constituents is maintained at a constant level.
Another great challenge besides increasing the productivity is to achieve appropriate downstream processability to enable tableting [24, 25]. In the case of water-based ES, the residual water content of the dried samples has great importance, because it has a high impact on the friability due to the water plasticizing effect [26]. In this respect, the grindability of the fibers and the properties (e.g. flowability) of the ground fibers are also critical. Furthermore, the water content could affect the API chemical and microbiological stability during long-term storage [27, 28]. The present research aimed to investigate the advantages of HSES method during the scale-up of waterbased ES for the solid formulation of biopharmaceuticals. Polyvinyl alcohol (PVA) was chosen as a basic polymer matrix for the aqueous electrospinning experiments as it shows good compatibility with biomolecules [29-31]. The development of a formulation consisting of polymers and excipients was carried out to achieve adequate fiber formation with high productivity and good downstream processability.

\section{Experimental}

\subsection{Materials}

Polyvinyl alcohol (PVA, $\left.M_{\mathrm{w}}: 130000 \mathrm{~g} / \mathrm{mol}\right)$ purchased from Sigma-Aldrich (Merck, Darmstadt, Germany) and polyethylene oxide (PEO, $M_{\mathrm{w}}$ : $2000000 \mathrm{~g} / \mathrm{mol}$ ) supplied by Colorcon (Dartford, England) were used as polymer matrices. Mannitol (Mannogem EZ, SPI Pharma, Wilmington, USA), glucose (glucose-monohydrate, Hungrana, Szabadegyháza, Hungary), lactose (lactose-monohydrate, Meggle Pharma, Wasserburg, Germany), saccharose (Reanal, Budapest, Hungary) and trehalose (trehalose dihydrate, Sigma-Aldrich, St. Louis, USA) were used as additives to enhance the grindability. Distilled water was used to prepare the polymer solutions for electrospinning.

\subsection{Viscosity measurement}

The viscosity of the solutions was determined using an AR 2000 rotational rheometer (TA Instruments, New Castle, USA) in parallel plate configuration. The upper moving plate of $40 \mathrm{~mm}$ diameter and the lower Peltier plate, which set the temperature of the solutions to $25^{\circ} \mathrm{C}$, were made of stainless steel. The viscosities were measured at linearly increasing shear rate from 20 to $60 \mathrm{1} / \mathrm{s}$. There were no practically 
relevant changes in the measured viscosities as a function of shear rate.

\subsection{Electrospinning technologies}

\subsubsection{Single-droplet electrospinning (SDES)}

SDES technology was used for the screening of polymer concentration required for obtaining fibers. One droplet of the polymer solution was placed on top of a metal $\operatorname{rod}(d=5 \mathrm{~mm})$ and high voltage $(20 \mathrm{kV}$ DC) was applied provided by an NT-35 direct current power supplier (MA2000, Unitronik Ltd, Nagykanizsa, Hungary). The fibers were collected on a grounded aluminum foil immobilized to the collector plate. The metal tip and the collector were vertically at a distance of $15 \mathrm{~cm}$ (see Figure 1a).

\subsubsection{Single-needle electrospinning (SNES)}

Lab-scale electrospinning device, SNES was used with a $0.5 \mathrm{~mm}$ inner diameter nozzle which was connected with high voltage supply and the polymer solution was dosed by a SEP-10S Plus type syringe pump (Aitecs, Vilnius, Lithuania) (see Figure 1b). The electrical potential applied on the nozzle, the collector distance, and the feeding was $20-30 \mathrm{kV}, 15-30 \mathrm{~cm}$, and $0.5-1 \mathrm{ml} / \mathrm{h}$ respectively, furthermore it was adjusted for each solution to obtain adequate fiber formation. All of the experiments were carried out at room temperature.

\subsubsection{High-speed electrospinning (HSES)}

The scaled-up electrospinning experiments were performed using a high-speed electrostatic spinning setup consisting of a round-shaped, stainless steel atomizer connected to a high-speed motor [23]. The high rotation speed of the atomizer and the multiple holes in it (number of holes: 8, diameter of the holes: $330 \mu \mathrm{m}$, diameter of the atomizer $34 \mathrm{~mm}$ ) allowed higher productivity. The polymer solution was fed with a syringe pump (SEP-10S Plus, Aitecs, Vilnius, Lithuania) at

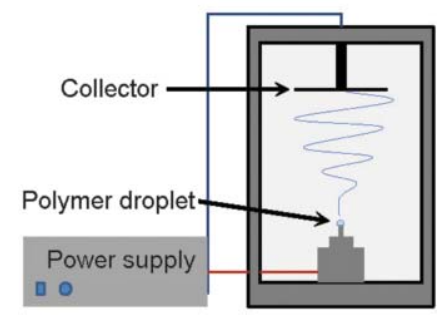

a)

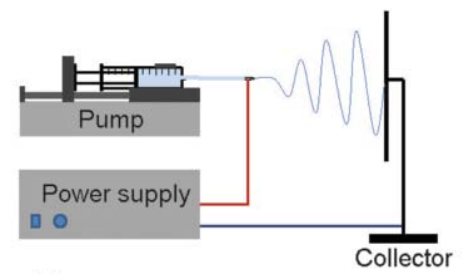

b)
$20-80 \mathrm{ml} / \mathrm{h}$. The rotational speed of the atomizer (2000-9000 rpm), and the voltage applied (0-40 kV) were tested during the experiments. A drying air flow ( 2 bar) and the electrostatic forces directed the fibers to the grounded metal collector covered with aluminum foil, which was at a fixed distance $(35 \mathrm{~cm})$ from the spinneret in a vertical arrangement (see Figure 1c). The experiments were performed at room temperature.

\subsection{Post drying}

Post drying was carried out in a vacuum oven (Vaciotem-T, JP Selecta, Barcelona) at $25^{\circ} \mathrm{C}$ and 0.05 bar. The fibers were dried for 48 hours.

\subsection{Grinding}

The nanofibers were ground using different technologies in order to evaluate the friability of the fibers. A sieve with $0.8 \mathrm{~mm}$ grid, a cutting mill (IKA A11., IKA-WERKE GmbH \& Co. KG, Staufen, Germany) at $28000 \mathrm{rpm}$, and a hammer mill (IKA MF10, IKAWERKE GmbH \& Co. KG, Staufen, Germany) with $1 \mathrm{~mm}$ grid and $3000 \mathrm{rpm}$ were used in the experiments.

\subsection{Scanning electron microscopy (SEM)}

Morphology of the samples was examined by a JEOL 6380LVa (JEOL, Tokyo, Japan) type scanning electron microscope in high vacuum after electrospinning and grinding. Samples were fixed by conductive double-sided carbon adhesive tape and coated with gold using ion sputter (JEOL 1200, JEOL, Tokyo, Japan). The applied accelerating voltage was $15 \mathrm{kV}$ and the working distance was between $10-30 \mathrm{~mm}$.

\subsection{Water content measurement}

The water content of the samples was measured right after the electrospinning process and after the postdrying using a moisture balance (Sartorius MA40,

Figure 1. Schematic representation of SDES equipment (a) used for polymer screening, SNES equipment (b) used for the lab-scale experiment, and a scaled-up electrospinning set-up, HSES equipment (c). 
Sartorius, Göttingen, Germany). The water content was determined based on the weight loss of approximately $0.1 \mathrm{~g}$ sample after $10 \mathrm{~min}$ at $105^{\circ} \mathrm{C}$.

\subsection{Particle size distribution measurement}

The particle size distribution was measured with a Mastersizer 2000 (Malvern Instruments Ltd., Malvern, UK) laser diffraction-based particle size analyzer.

\subsection{Raman spectroscopy}

A Kaiser RamanRxn2 ${ }^{\circledR}$ Hybrid in-situ analyzer (Kaiser Optical Systems, Ann Arbor, USA) connected with PhAT (Pharmaceutical Area Testing) probe was applied to acquire the spectra of the fibrous samples for the characterization of the crystallinity of the compounds. The samples were illuminated with an Invictus laser diode (400 mW, $785 \mathrm{~nm}$ ). Reflection mode was used for measuring reference samples and fibers. The diameter of the laser spot size was extended to $6 \mathrm{~mm}$ and the nominal focus length was $250 \mathrm{~mm}$. The examined spectral range was between 200 and $1890 \mathrm{~cm}^{-1}$. During the measurements, the resolution was $4 \mathrm{~cm}^{-1}$, which provided 1691 variables during data processing. An acquisition time of 60 seconds gave adequate Raman intensity and signal-to-noise ratio. The wavenumbers between $1532-300 \mathrm{~cm}^{-1}$ was included for analysis, because there were no characteristic peaks in this region. The spectra were baseline corrected (Automatic Whittaker Filter) and normalized $($ area $=1)$ using MATLAB software.

\subsection{X-ray diffraction (XRD)}

$\mathrm{X}$-ray diffraction patterns were recorded with a PANalytical X'pert Pro MDP X-ray diffractometer (Almelo, The Netherlands) using Cu-Ka radiation (1.506 $\AA$ ) and Ni filter. The applied voltage was $40 \mathrm{kV}$, while the current was $30 \mathrm{~mA}$. The reference samples and the fibrous samples were analyzed between $2 \theta$ angles of 4 and $42^{\circ}$.

\section{Results and discussion}

The morphology of the fibers produced by electrospinning (ES) can be affected by solution parameters such as composition and viscosity (i.e. through component concentrations and component type), and process parameters such as applied voltage, feeding rate, and the collector distance. The influence of the polymer concentration on morphology and fiber diameter was studied using single-droplet electrospinning (SDES, Figure 1a). The electrospinning process using aqueous polyvinyl alcohol (PVA) solutions was transferred to the single-needle electrospinning (SNES, Figure 1b) device and the feasibility of scale-up was evaluated using high-speed electrospinning (HSES, Figure 1c). The SDES, SNES, and HSES manufacturing techniques were compared with respect to fiber morphology and productivity. The solution composition was modified with different excipients to obtain grindable fibers.

The aim of the study was to produce fibers with the smallest possible fiber diameter, high productivity, and good grindability. Finally, the formulations were characterized based on water content, crystallinity, and physical stability.

\subsection{Screening of fiber formation of aqueous PVA solution}

For the fast evaluation of fiber formation, SDES technology was used, requiring only a small amount (approximately $200 \mu \mathrm{l}$ ) of polymer solution. With increasing polymer concentration the viscosity of the solutions increased as well, which has a large effect on product morphology [32]. Several polymer solutions with different PVA concentration (4.8, 9.1, $13.0,14.9,16.7 \%$, throughout the article all concentrations are given as $\mathrm{w} / \mathrm{w} \%$ ) were prepared and electrospun. Electrospinning of polymer solutions with too low concentration results in the formation of particles. By increasing the concentration, shape of the particles changes to fibers. At an optimal concentration range, stable and reproducible fiber production can be attained. Fiber diameter can be increased using higher viscosity solutions; however, using too high polymer concentrations, the highly viscous solutions can cause problems during feeding as they cannot be pumped.

The results of SDES shown in Figure 2 were evaluated based on fiber formation and fiber diameter of the formulations. Fibers were not formed at $4.8 \%$ due to the viscosity being too low, while as soon as the viscosity was increased to ca. $250 \mathrm{mPa} \cdot \mathrm{s}$ fiber formation occurred. For all PVA concentrations higher than or equal to $9.1 \%$ fibers were formed with average diameters in the submicron range. As expected fiber diameter increased with increasing concentration due to the higher viscosity. The solution containing $16.7 \%$ PVA was too viscous for further experiments using a syringe pump. 


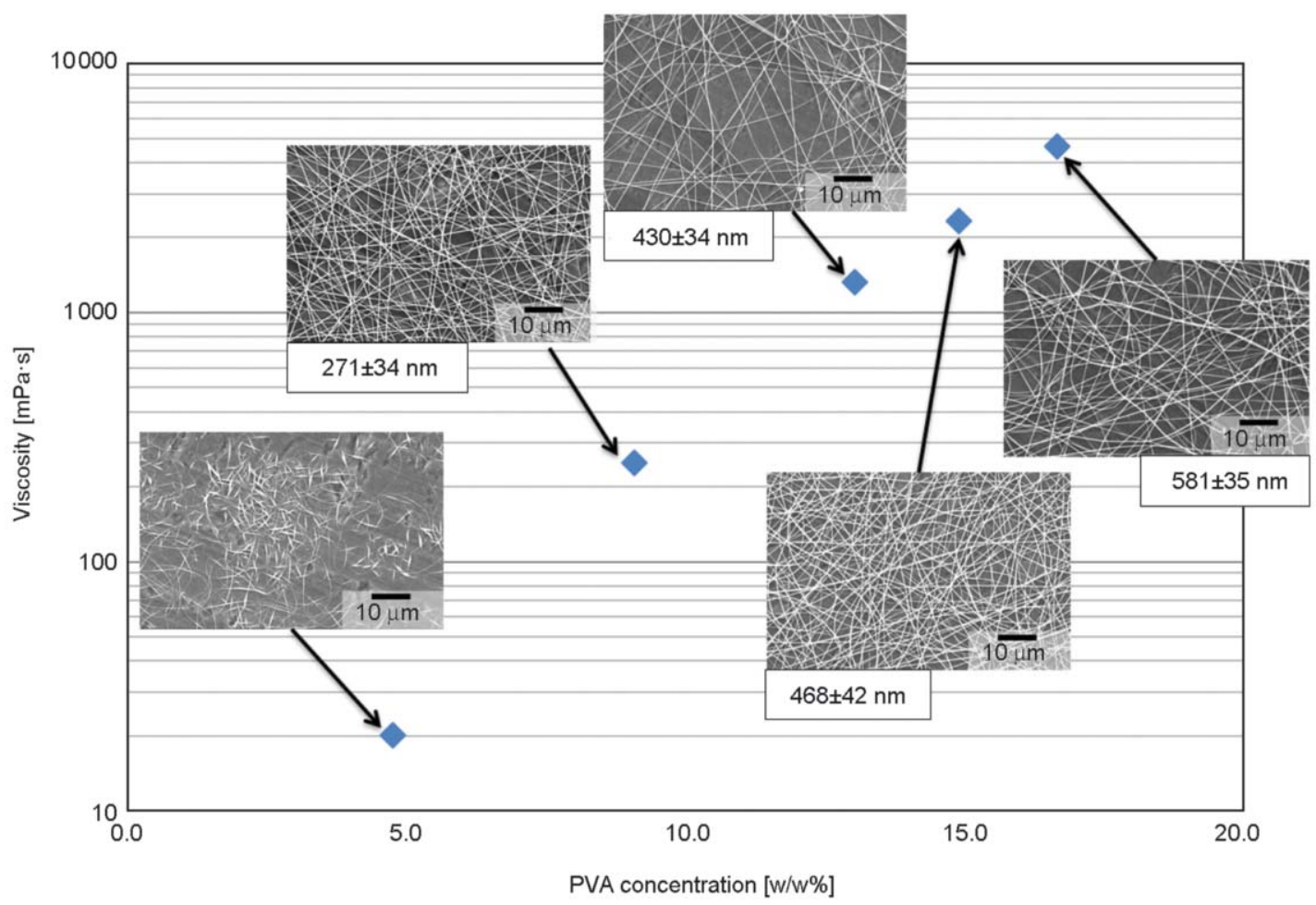

Figure 2. The viscosity of the PVA aqueous solutions and the obtained fiber morphology using SDES. Scanning electron microscope (SEM) images of the fibers were taken and the average fiber diameter of each formulation was calculated from 10 measurements.

Table 1. Average fiber diameter and standard deviation (SD) (calculated from 10 measurements) of the formulations obtained from 9.1, 13.0 and 14.9\% PVA aqueous solution using SDES, SNES, and HSES electrospinning methods.

\begin{tabular}{|c|c|c|c|c|c|c|c|}
\hline \multirow[b]{2}{*}{ ES method } & \multicolumn{2}{|c|}{$9.1 \%$ PVA } & \multicolumn{2}{|c|}{$13.0 \%$ PVA } & \multicolumn{2}{|c|}{$14.9 \%$ PVA } & \multirow{2}{*}{$\begin{array}{l}\text { Productivity } \\
{[\mathrm{g} / \mathrm{h}]}\end{array}$} \\
\hline & $\begin{array}{c}\text { Fiber diameter } \\
{[\mathbf{n m}]}\end{array}$ & $\begin{array}{c}\text { SD } \\
{[\mathrm{nm}]}\end{array}$ & $\begin{array}{c}\text { Fiber diameter } \\
{[\mathrm{nm}]}\end{array}$ & SD & $\begin{array}{c}\text { Fiber diameter } \\
{[\mathrm{nm}]}\end{array}$ & $\begin{array}{c}\text { SD } \\
{[\mathrm{nm}]}\end{array}$ & \\
\hline SDES & 271 & 34 & 430 & 34 & 468 & 42 & - \\
\hline SNES & 279 & 41 & 427 & 43 & 445 & 80 & $0.045-0.075$ \\
\hline HSES & 232 & 41 & 398 & 61 & 477 & 109 & $3.6-6.0$ \\
\hline
\end{tabular}

\subsection{Comparison of electrospinning methods}

SDES, SNES, and HSES were compared with respect to applicability for water-based electrospinning. For the comparison, solutions containing 9.1 $13.0,14.9 \%$ PVA were prepared as these concentrations were known to form fibers and were feasible for production. The methods were evaluated based on fiber morphology, and productivity and the results are shown in Table 1.

The fiber diameters and morphology obtained using SDES were similar to SNES and HSES, which also shows the feasibility of SDES technology for screening. Using HSES, the fiber diameters were slightly smaller for 9.1 and $13.0 \%$ PVA concentrations and bigger for the highest concentration; however, there was an increase in the standard deviation. The apparent smaller fiber diameters and wider fiber distributions are likely caused by the rotating spinneret i.e. both electrostatic and centrifugal forces for the atomization (Table 1).

Using SNES the maximal feeding rate for the waterbased systems proved to be $0.5 \mathrm{ml} / \mathrm{h}$, which is very low even in laboratory scale (maximum $75 \mathrm{mg} / \mathrm{h}$ ). In comparison, using HSES $40 \mathrm{ml} / \mathrm{h}$ (maximum $6 \mathrm{~g} / \mathrm{h}$ ) feeding rate could be achieved, however, the experiment resulted not only in fiber production but droplets were also detected on the collector (Figure 3 ) indicating that either process conditions or solution composition should be optimized to further improve fiber formation, and this will be discussed in the next section.

\subsection{Optimization of solution formulation}

When HSES was used for the formulation of PVA aqueous solution, besides fiber formation droplets were also detected on the collector, owing to the high 
breakage ratio of the jet to droplets at the nozzle. In the PVA aqueous solution the entanglement of the polymer chains is low due to the hydrogen bonds between the polymer chains and the water molecules [33]; however, if the entanglement is sufficiently high, then fiber formation takes place [34, 35]. Using higher PVA concentration (13.0 and 14.9\%) with higher viscosity was not suitable to increase the entanglement and resulted in droplets and fibers on the collector.

\subsubsection{Role of PEO}

Another strategy for reducing the droplet formation was to add high molecular weight polyethylene oxide (PEO) in low concentration to the PVA solution. PEO is a really good fiber forming polymer, thus it can help the fiber formation of various blends [36, 37]. PEO can interact with the PVA molecules by competing with water molecules and combined with the larger molecule size results in an increase of the entanglement.

Different concentrations of PEO $(0.5,0.7,0.9,1.4 \%)$ were added to the PVA solution. By adding $1.4 \%$ $\mathrm{PEO}$, the fiber formation was adequate and there were no droplets on the collector while adding $0.9 \%$ or less PEO, several droplets could be found on the collector. The droplet formation is shown in Figure 3 as a function of PEO concentration. The PEO containing formulations had larger fiber diameters, which slightly increased with the PEO concentration but only within the range of standard deviation.

The viscosity of the solution containing 9.0\% PVA and $1.4 \% \mathrm{PEO}$ was $1420 \mathrm{mPa} \cdot \mathrm{s}$ which is comparable to the $13.0 \%$ PVA solution's viscosity $(1320 \mathrm{mPa} \cdot \mathrm{s})$, however, in the presence of $1.4 \%$ PEO, the droplet formation could be avoided. The entanglement of the polymer chains in the PVA solution was increased by the addition of PEO, which resulted in adequate fiber formation (no droplets), but with an increase in fiber diameter of $\sim 50 \%$ (to 367 from $232 \mathrm{~nm}$ ). While the fiber quality and process productivity met the desired targets (wrt. morphology and production rate), the fibrous mat was sticky and the grinding was not possible, which is an important attribute in downstream processing. Consequently, while the use of $\mathrm{PEO}$ as a secondary polymer is a feasible solution to prevent droplet formation during water-based ES, further optimization is needed in order to improve the grindability.

\subsubsection{Grindability optimization}

Processability of the fibers (e.g. milling, powder properties, etc.) is a critical aspect for the development of solid pharmaceutical products. The produced

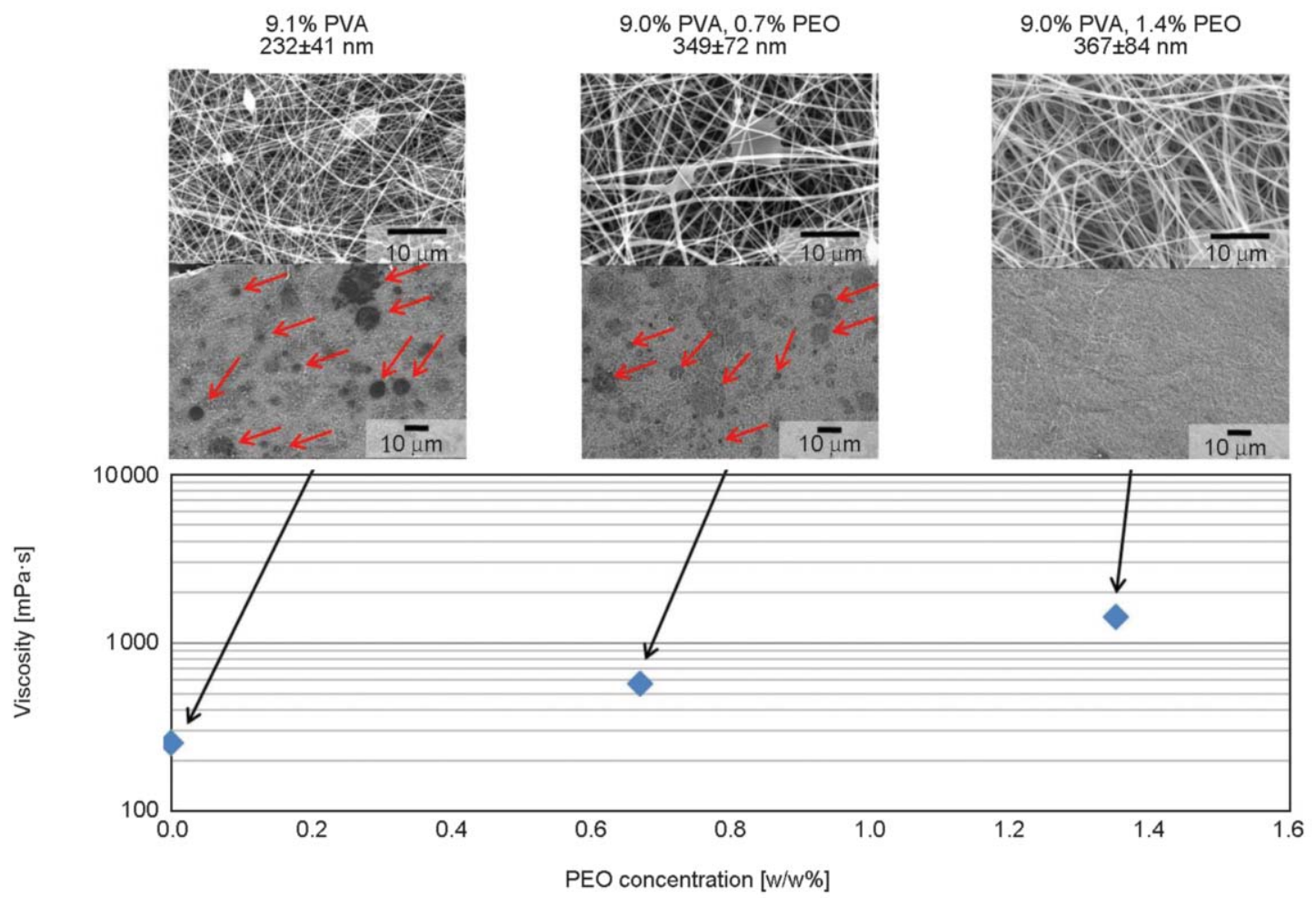

Figure 3. SEM images of electrospun fibers from PVA and PEO containing solution using HSES. Droplet formation, viscosity, and fiber diameter as a function of PEO concentration. Droplets are indicated with arrows. 
fibers are collected in a form of a fibrous mat, which cannot be directly used for the production of a tablet, hence the fiber mat needs to be grounded to a powder before further processing. Therefore, the optimization of the polymer matrix was carried out considering the grindability of the fibers. The composition of the electrospinning solution was modified in order to adjust both the grindability and spinnability using HSES, which was applied in the subsequent experiments.

From biopharmaceutical formulations of freeze and spray drying it is a well-known strategy to use sugars to protect the molecules during drying and for

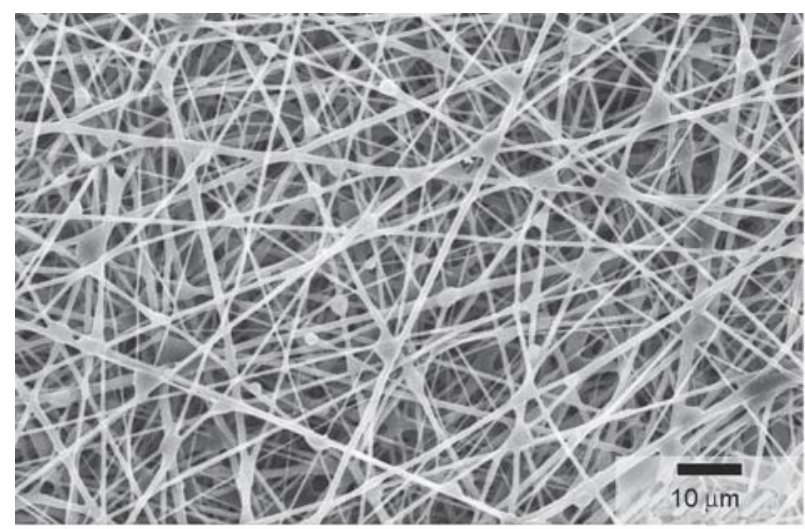

$$
\text { a) }
$$

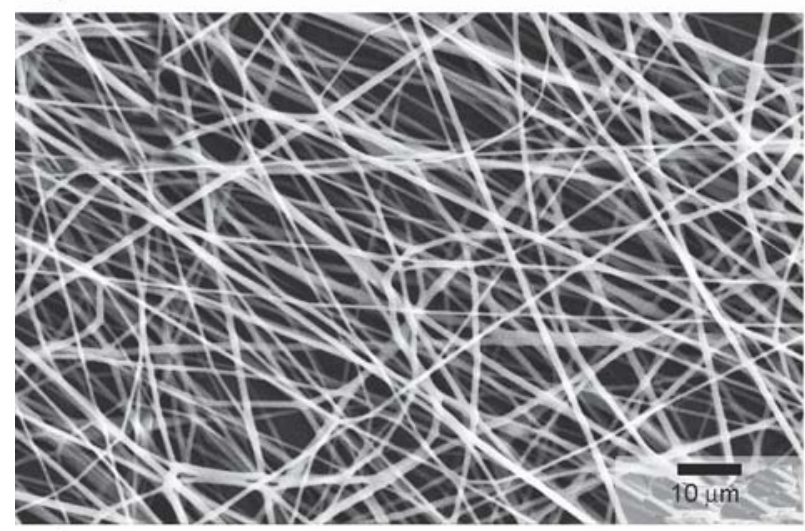

processing [13], therefore it was decided to investigate the impact of the following 5 sugars: glucose, lactose, mannitol, saccharose, and trehalose. The electrospinnability and grindability were evaluated in parallel, with the function of PEO concentration. The aim of the optimization was to obtain grindable fibers with the diameter in the submicron range using a robust electrospinning process without droplet formation. The minimal sugar concentration needed to obtain grindable fibers was determined by adding different amount of mannitol to the PVA-PEO solution. The use of twice as much mannitol as polymer resulted in fibers with adequate grindability.

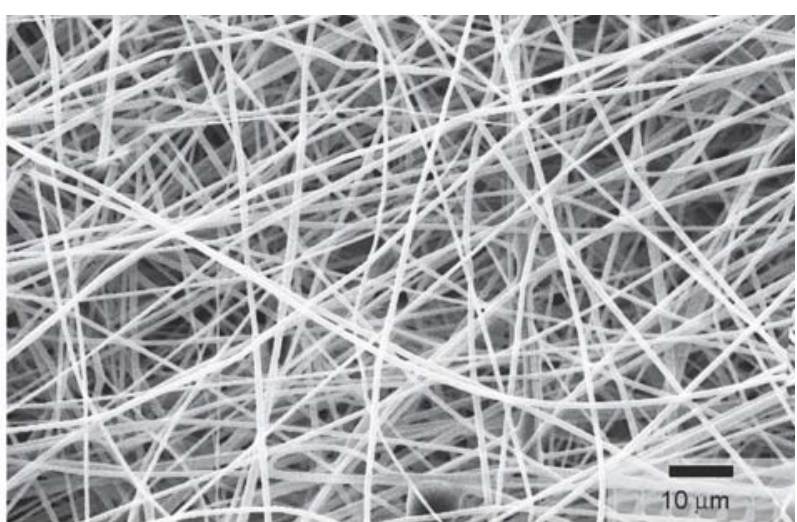

b)

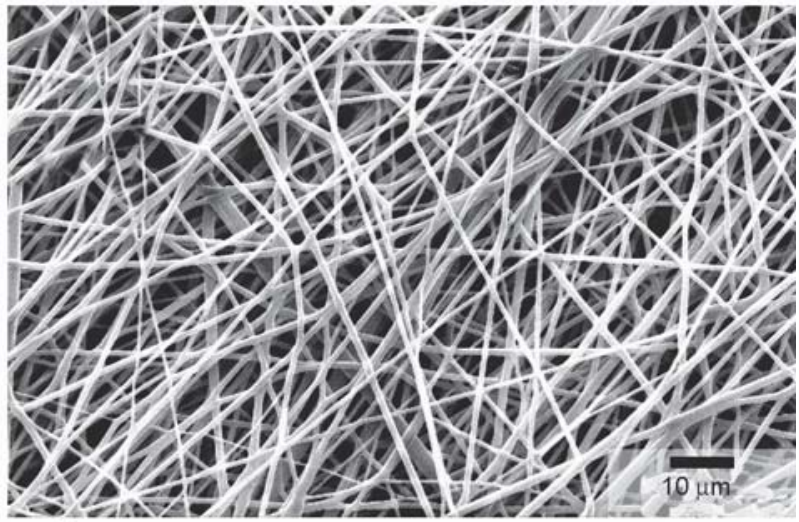

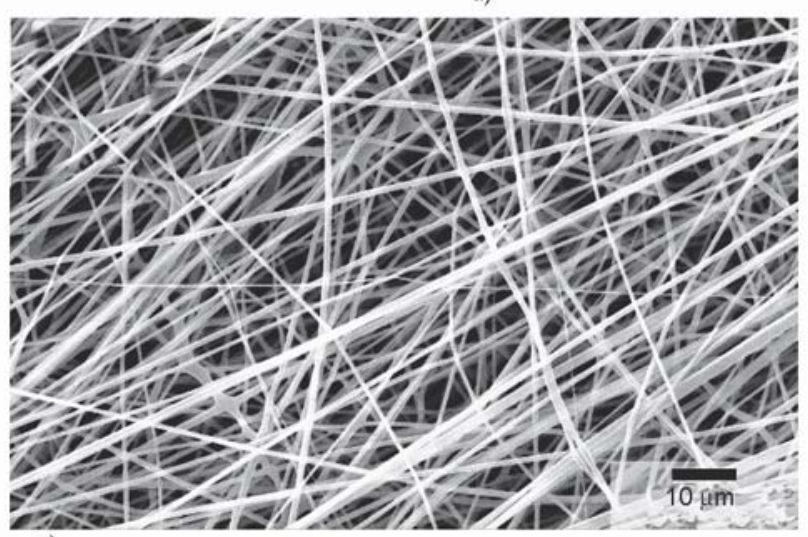

e)

Figure 4. SEM images of PVA-PEO fibers containing a) glucose, b) lactose, c) mannitol, d) saccharose, and e) trehalose produced with HSES equipment. 
To prevent the droplet formation during ES, different concentrations $(0.4,0.6,0.8,1.1 \%)$ of PEO were added to the PVA solution containing mannitol as a grinding aid. High concentration of PEO can increase the fiber diameter and decrease the grindability of the fibers, thus the minimal concentration needed to be found. The composition containing $0.4 \%$ PEO resulted in droplets on the collector. Fiber formation was adequate and there was no droplet formation from the aqueous solution containing 7.7\% PVA, $0.6 \%$ PEO and $15.3 \%$ mannitol. However, the fiber diameter increased $(856 \pm 214 \mathrm{~nm})$ with the addition of mannitol but it was necessary as it was needed to modify the formulation to achieve good grindability. The use of 0.8 and $1.1 \%$ PEO increased the fiber diameter (to 750 and $1120 \mathrm{~nm}$ ) further, which was not preferred.

Besides mannitol, glucose, lactose, saccharose, and trehalose were used to enhance the grindability of PVA-PEO fibers. The solutions prepared for electrospinning contained $7.7 \%$ PVA, $0.6 \%$ PEO, and $15.3 \%$ sugar based on the mannitol optimization. Using each grindability aid the fiber formation was adequate and there was no droplet formation, the fibers are shown in Figure 4. The average diameter of the fibers using mannitol, glucose, lactose, saccharose, and trehalose was 856, 908, 895, 912, and $969 \mathrm{~nm}$ respectively with similar standard deviation (Table 2). The increased total concentration of the polymer solution (10.5 to $23.6 \%)$ can be the reason for the increased fiber diameter compared to the formulations without sugars. The viscosity of the solutions containing different sugar-type excipients was between 644 and $713 \mathrm{mPa} \cdot \mathrm{s}$ (Table 2) which was lower compared to the solution containing only PVA and PEO (viscosity $1420 \mathrm{mPa} \cdot \mathrm{s}$ ). The sugar molecules make secondary interaction with the water molecules removing them from the PVA hydrogen bonds and creating an emulsion-like structure. The disruption of

Table 2. Viscosity of 7.7\% (1.00 g) PVA, $0.6 \%(0.08 \mathrm{~g})$ PEO, and $15.3 \%$ (2.00 g) sugar-containing aqueous solutions $(10 \mathrm{ml})$ and the average fiber diameter obtained using HSES.

\begin{tabular}{|l|c|c|c|}
\hline $\begin{array}{c}\text { Sugar } \\
\text { excipient }\end{array}$ & $\begin{array}{c}\text { Viscosity } \\
{[\mathbf{m P a} \cdot \mathbf{s}]}\end{array}$ & $\begin{array}{c}\text { Fiber diameter } \\
{[\mathbf{n m}]}\end{array}$ & $\begin{array}{c}\text { SD } \\
{[\mathbf{n m}]}\end{array}$ \\
\hline Mannitol & 683 & 856 & 214 \\
\hline Glucose & 713 & 908 & 319 \\
\hline Saccharose & 644 & 912 & 180 \\
\hline Lactose & 704 & 895 & 294 \\
\hline Trehalose & 675 & 969 & 318 \\
\hline
\end{tabular}

the hydration layer of the PVA resulted in higher entanglement of the polymer chains. The minimal PEO concentration needed to prevent droplet formation also decreased in the presence of sugars. The high entanglement of the polymer molecules made the fiber formation possible at lower viscosity.

\subsection{Screening of process parameters}

Besides solution composition, process parameters have a high impact on fiber formation and morphology [7]. Thus, screening of the feeding rate, the rotational speed of the atomizer and the applied voltage was carried out using HSES with a solution containing $7.7 \%$ PVA, $0.6 \%$ PEO and $15.3 \%$ mannitol (Table 3). Rotational speed and feeding rate had no significant effect on the fiber diameter and fiber formation in the examined range; however, the increase of the feeding rate resulted in droplet formation. When using $60 \mathrm{ml} / \mathrm{h}$ or higher feeding rates, droplet and fiber formation could be observed during the ES process. High voltage of 0, 20, and $40 \mathrm{kV}$ was applied to the atomizer. With the decrease of voltage, there was an increase in fiber diameter, which is expected as fiber formation and size is controlled by the electrostatic force [V] and centrifugal force [rpm]. The optimal parameters were: $9000 \mathrm{rpm}, 40 \mathrm{kV}$, and the feeding rate could be raised up to $40 \mathrm{ml} / \mathrm{h}$ in HSES experiments, which is an 80 times higher production rate compared to SNES.

\subsection{Characterization}

\subsubsection{Effect of water content on grindability}

The grindability of the fibers is an important aspect of the downstream proceassability to obtain a final

Table 3. Screening of process parameters during high-speed electrospinning using a solution containing 7.7\% PVA, $0.6 \%$ PEO and $15.3 \%$ mannitol.

\begin{tabular}{|c|c|c|c|c|}
\hline $\begin{array}{c}\text { Dosing } \\
\text { speed } \\
{[\mathbf{m l} / \mathbf{h}]}\end{array}$ & $\begin{array}{c}\text { Rotational } \\
\text { speed } \\
{[\mathbf{r p m}]}\end{array}$ & $\begin{array}{c}\text { Voltage } \\
{[\mathbf{k V}]}\end{array}$ & $\begin{array}{c}\text { Fiber } \\
\text { diameter } \\
{[\mathbf{n m}]}\end{array}$ & SD \\
\hline 20 & 9000 & 40 & 883 & 308 \\
\hline 40 & 9000 & 40 & 901 & 220 \\
\hline 60 & 9000 & 40 & 883 & 163 \\
\hline 80 & 9000 & 40 & 1069 & 296 \\
\hline 40 & 2000 & 40 & 890 & 278 \\
\hline 40 & 4500 & 40 & 1071 & 322 \\
\hline 40 & 9000 & 40 & 901 & 220 \\
\hline 40 & 9000 & 0 & 1689 & 372 \\
\hline 40 & 9000 & 20 & 1279 & 391 \\
\hline 40 & 9000 & 40 & 901 & 220 \\
\hline & & & & \\
\hline
\end{tabular}


dosage form e.g. tablet. The grindability of the PVAPEO-sugar formulations was tested using a sieve, a cutting mill, and a hammer mill. Comparing the different grinding technologies, the hammer mill was chosen for further examination because it can be integrated in a continuous technology line. The ground materials obtained using the hammer mill were characterized and SEM images were taken before and after milling to investigate milling impact on fiber characteristics.

The fibrous mats recovered from HSES were typically $2 \mathrm{~cm} \times 5 \mathrm{~cm}$. The milling converted the mats to

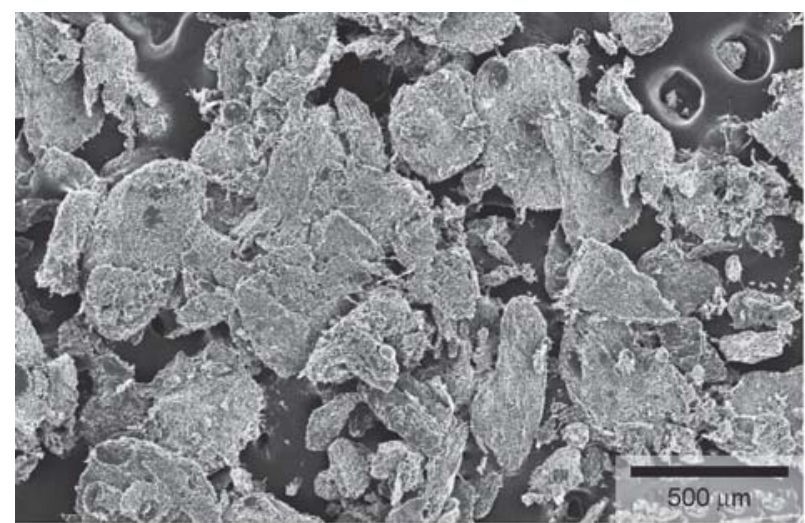

a)

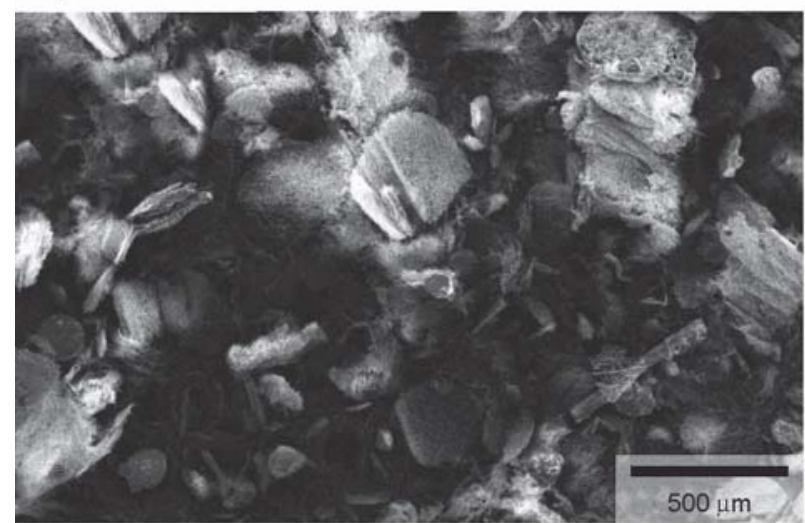

c)

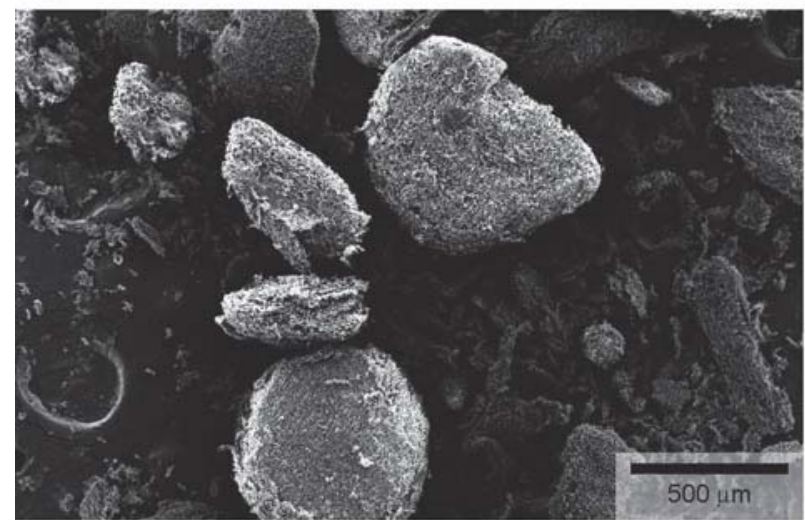

e) micron-sized particles as seen in Figure 5 composed of submicron fibers (Figure 5d). The morphology was not affected by the grinding. The fibers were easily milled and non-sticking to the mill. The particle size distribution of the milled powders is shown in Table 4, and it can be observed that the average particle size after milling was similar for the formulations with glucose, mannitol, and lactose, but slightly higher for the formulations with saccharose and trehalose. All five produced powder had low-density (e.g. $0.0385 \mathrm{~g} / \mathrm{cm}^{3}$ for mannitol) with poor flowability. From the particle size, good flowability would

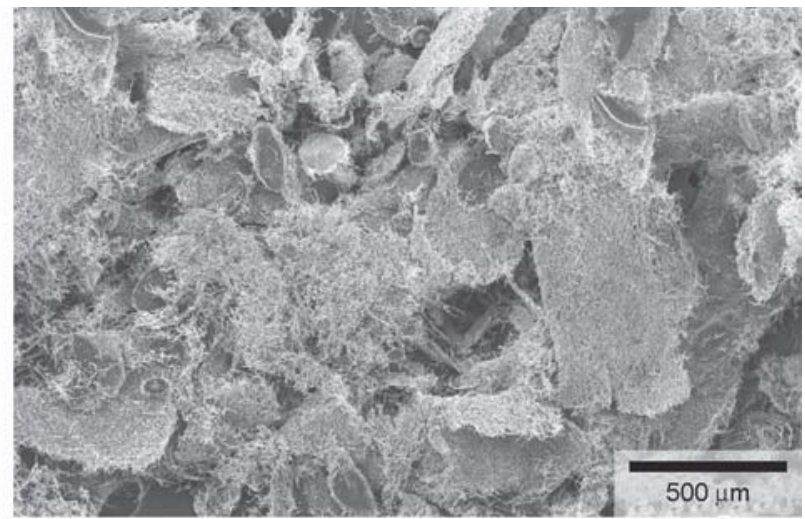

b)

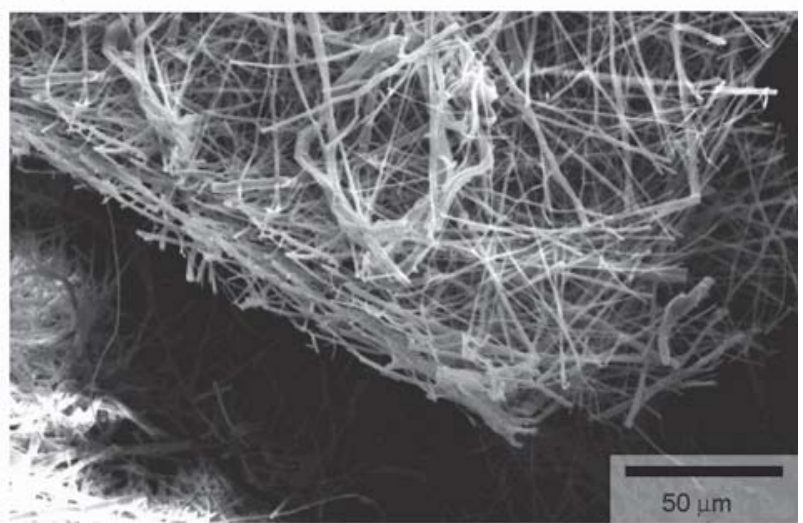

d)

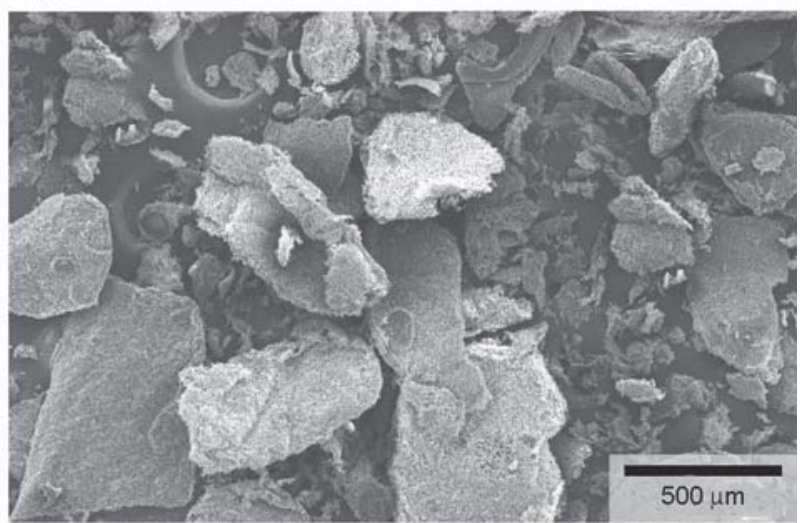

f)

Figure 5. SEM images of ground PVA-PEO-Sugar fibers containing a) glucose, b) lactose, c)-d) mannitol, e) saccharose, and f) trehalose. Electrospinning was accomplished using HSES and the obtained nanofibrous mats were ground using a hammer mill. 
Table 4. Particle size distribution of ground PVA-PEO-Sugar fibers. D-values (D10, D50, D90) were used to describe particle size distributions, which are the intercepts for the particle size of the 10,50 and $90 \%$ of the cumulative mass.

\begin{tabular}{|lc|c|c|c|c|c|}
\hline & Glucose & Mannitol & Lactose & Saccharose & Trehalose \\
\hline D10 & {$[\mu \mathrm{m}]$} & 94 & 65 & 101 & 58 & 96 \\
\hline D50 & {$[\mu \mathrm{m}]$} & 338 & 318 & 325 & 375 & 407 \\
\hline D90 & {$[\mu \mathrm{m}]$} & 669 & 696 & 657 & 841 & 821 \\
\hline (D90-D10)/D50 & 1.70 & 1.98 & 1.71 & 2.09 & 1.78 \\
\hline
\end{tabular}

Table 5. Water content $\left(\mathrm{H}_{2} \mathrm{O} \%\right)$ and grindability of the fibrous mat containing different sugars.

\begin{tabular}{|l|l|c|c|c|c|c|}
\hline \multicolumn{2}{|c|}{} & Glucose & Mannitol & Lactose & Saccharose & Trehalose \\
\hline \multirow{2}{*}{ After HSES } & $\mathrm{H}_{2} \mathrm{O}[\%]$ & 13.3 & 5.5 & 11.2 & 9.4 & 14.0 \\
\cline { 2 - 8 } & Grindable? & $\mathrm{NO}$ & YES & NO & NO & NO \\
\hline \multirow{2}{*}{ After post-drying } & $\mathrm{H}_{2} \mathrm{O}[\%]$ & 7.1 & 3.7 & 4.7 & 5.7 & 7.8 \\
\cline { 2 - 7 } & Grindable? & YES & YES & YES & YES & YES \\
\hline
\end{tabular}

be expected, however, due to the fibrous structure, the particles had poor flowability. While the five formulations (cf. Table 2) have similar properties further characterization of the produced powders is necessary in order to understand the impact of milling. The formulation containing mannitol was grindable right after the electrospinning process; however, the samples containing glucose, lactose, saccharose, and trehalose were too sticky to be ground. It was assumed that this was caused by the high water content of the powder, with water acting as a plasticizer and this was confirmed by water content measurements with the results shown in Table 5. In order to see if a grindable product could be obtained; all formulations were post dried to achieve lower water content. After postdrying, all sugar containing formulations were grindable and thereby suitable for downstream processing (Table 5). The water content influenced the grindability of the samples significantly, due to its plasticizing effect, and by lowering the water content the fibers were friable which enhanced the grindability.

\subsubsection{Physical state of the fibers}

Pharmaceutically used sugars have different water sorption capability depending on their physical state (crystalline or amorphous) [38]. Crystalline sugars interact with water based on surface adsorption; meanwhile, amorphous materials absorb a large number of water molecules into the bulk structure. The moisture content, hence also the downstream processability of the samples, is influenced by not only the drying conditions but also the physical state of the substances [39].
Thus, the physical state of the polymers and excipients were examined using X-ray diffraction (XRD) and Raman spectrometry. The polymers (PVA and PEO) proved to be amorphous in each formulation and were stable over the examined 3 months (Figure 6). Mannitol was crystalline and the $\delta$ polymorph was present in the fibers, which was proven by the characteristic peaks of the $\delta$ polymorph shown on the Raman and XRD spectra (Figure 6,7).

On the contrary, the glucose, lactose, saccharose, and trehalose containing formulations showed peak widening and shifting due to their amorphous structure. Over the 3 months storage at low humidity conditions, the samples containing lactose, saccharose, and trehalose preserved the amorphous state, while glucose crystallized over the storage time (Figure 6,7). Amorphous solids are in not-equilibrium state, in some cases crystalline transition takes place. Further characterization will be needed to investigate the influencing factors of the phenomenon.

Crystallinity, such as in the case of mannitol, can be advantageous to achieve enhanced grindability, due to the low water content and the friable nature of the sample. On the other hand, glucose, lactose, saccharose, and trehalose containing formulations were amorphous and had higher water content. The amorphous formulations were also friable after post-drying and the samples were grindable only at low water content. It can be concluded that the influencing factors of the grindability of fibers were not only the fiber formation and drying conditions but also the water content and the physical state of the excipients. While post drying was necessary for glucose, lactose, saccharose, and trehalose containing formulations, 


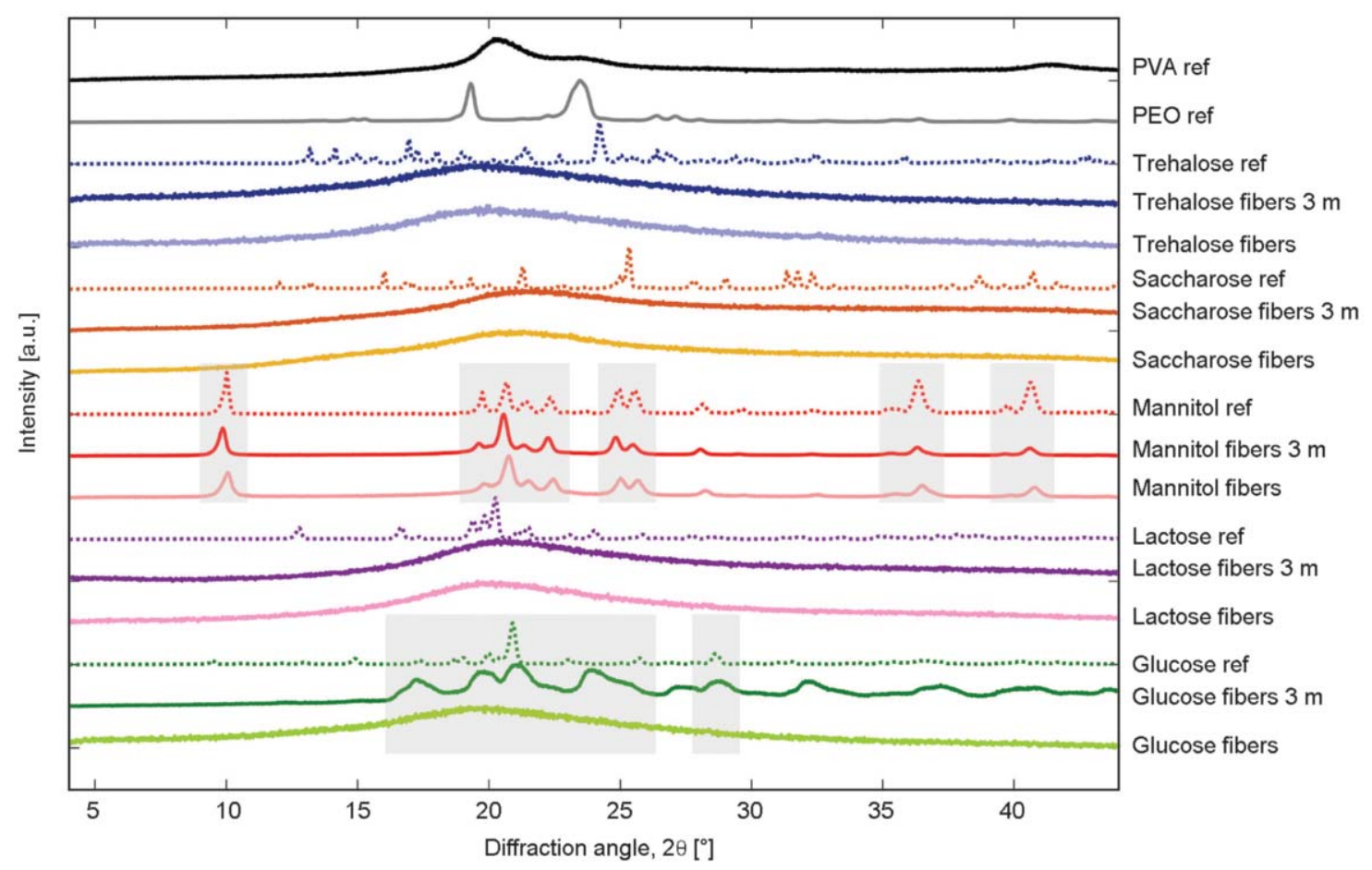

Figure 6. XRD graph of references and PVA-PEO-sugar fibers right after electrospinning and post-drying. XRD measurements were done after 3 months storage in low humidity conditions to study the stability of the components (curves indicated with $3 \mathrm{~m}$ ).

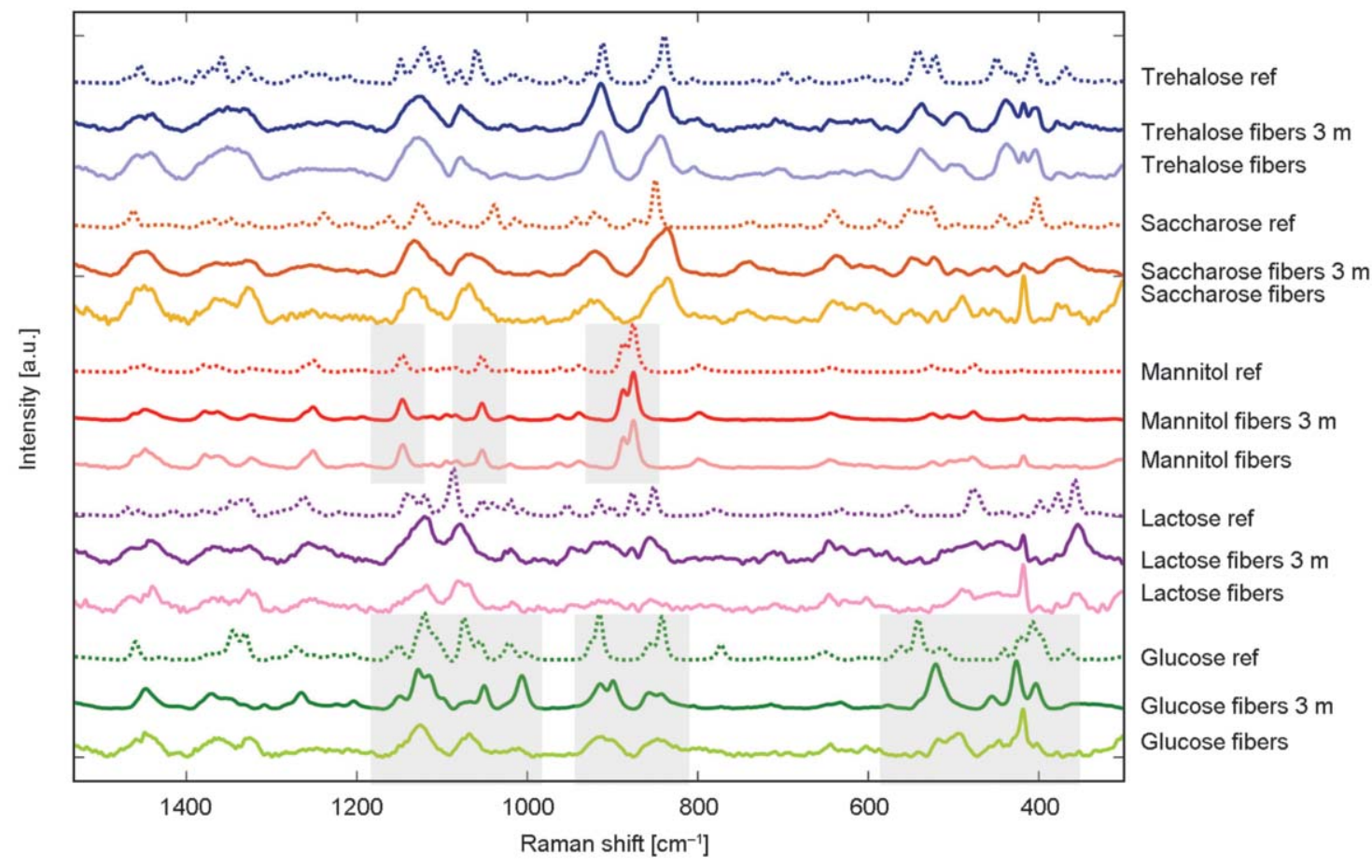

Figure 7. Raman spectra of references and PVA-PEO-sugar fibers right after electrospinning and post-drying, and after 3 months $(3 \mathrm{~m})$ storage in low humidity conditions.

it's possible that it can be avoided by further optimizing the ES conditions.

\section{Conclusions}

The capability of fiber formation from polyvinyl alcohol (PVA) aqueous solutions was examined using single-droplet electrospinning (SDES), single-needle electrospinning (SNES), and high-speed electrospinning (HSES) technologies. The scale-up and the optimization of the PVA system were carried out to achieve adequate fiber formation with high productivity and good downstream processability. 
SDES was found to be a feasible method for the fast screening of polymer concentration needed for fiber formation and the fiber diameter obtained using SDES was similar to SNES and HSES. The feeding rate during the electrospinning process could be raised from 0.5 to $40 \mathrm{ml} / \mathrm{h}$ using HSES equipment, which is an 80 times higher production rate compared to SNES. When HSES was used for the formulation of PVA aqueous solutions, fiber formation was achieved, but drying was incomplete as droplets were observed on the collector. The composition of the solution was modified to improve fiber formation using high molecular weight polyethylene oxide (PEO) in low concentration as a secondary polymer. While PVA-PEO formulations resulted in adequate fiber formation and productivity, it was not possible to process them further as the friability of the fibers was too low i.e. too sticky. The grindability of the fibers was enhanced by adding glucose, mannitol, lactose, saccharose, or trehalose to the polymer solution.

The PVA-PEO-sugar formulations resulted in grindable fibers in the submicron range though fiber diameter was increased compared to formulations without sugars. PVA and PEO polymers, as well as glucose, lactose, saccharose, and trehalose were amorphous and these fibrous samples were grindable only after a post-drying step due to the high moisture content and low friability of these samples. The water content influenced the grindability of the formulations significantly, due to its plasticizing effect, and by lowering the water content the fibers were friable which enhanced the grindability.

The use of mannitol was the most applicable as there was no need for post drying to achieve a grindable product after the electrospinning process. The low water content and the crystalline structure of mannitol in the fibrous sample is possibly the reason for the better grindability. It can be concluded that the influencing factors of the grindability of fibers were not only the fiber formation and drying conditions but also the formulation composition, final water content and the physical state of the excipients.

In this work, potential matrixes for the formulation of biopharmaceuticals were developed and characterized. The scale-up of the water-based electrospinning was accomplished using HSES technique, which shows a possible way for the solid formulation of highly sensitive biopharmaceuticals.

\section{Acknowledgements}

The research reported in this paper was supported by OTKA grants K-112644, PD-128241, KH-124541, and Ph.D. scholarship from Gedeon Richter's Talentum Foundation. Support of grant BME FIKP-BIO by EMMI is kindly acknowledged.

\section{References}

[1] Moroz E., Matoori S., Leroux J-C.: Oral delivery of macromolecular drugs: Where we are after almost 100 years of attempts. Advanced Drug Delivery Reviews, 101, 108-121 (2016).

https://doi.org/10.1016/j.addr.2016.01.010

[2] Maa Y-F., Prestrelski J. S.: Biopharmaceutical powders particle formation and formulation considerations. Current Pharmaceutical Biotechnology, 1, 283-302 (2000). https://doi.org/10.2174/1389201003378898

[3] Vass P., Démuth B., Hirsch E., Nagy B., Andersen S. K., Vigh T., Verreck T., Csontos I., Nagy Zs. K., Marosi Gy.: Drying technology strategies for colon-targeted oral delivery of biopharmaceuticals. Journal of Controlled Release, 296, 162-178 (2019).

https://doi.org/10.1016/j.jconrel.2019.01.023

[4] Langford A., Bhatnagar B., Walters R., Tchessalov S., Ohtake S.: Drying of biopharmaceuticals: Recent developments, new technologies and future direction. Japan Journal of Food Engineering, 19, 15-24 (2018). https://doi.org/10.11301/jsfe.18514

[5] Broeckx G., Vandenheuvel D., Claes J. J. I., Lebeer S., Kiekens F.: Drying techniques of probiotic bacteria as an important step towards the development of novel pharmabiotics. International Journal of Pharmaceutics, 505, 303-318 (2016). https://doi.org/10.1016/j.ijpharm.2016.04.002

[6] Huang S., Vignolles M-L., Chen X. D., Le Loir Y., Jan G., Schuck P., Jeantet R.: Spray drying of probiotics and other food-grade bacteria: A review. Trends in Food Science and Technology, 63, 1-17 (2017). https://doi.org/10.1016/j.tifs.2017.02.007

[7] Drosou C. G., Krokida M. K., Biliaderis C. G.: Encapsulation of bioactive compounds through electrospinning/electrospraying and spray drying: A comparative assessment of food-related applications. Drying Technology, 35, 139-162 (2017). https://doi.org/10.1080/07373937.2016.1162797

[8] Hu X., Liu S., Zhou G., Huang Y., Xie Z., Jing X.: Electrospinning of polymeric nanofibers for drug delivery applications. Journal of Controlled Release, 185, 1221 (2014).

https://doi.org/10.1016/j.jconrel.2014.04.018

[9] Jiang H., Wang L., Zhu K.: Coaxial electrospinning for encapsulation and controlled release of fragile watersoluble bioactive agents. Journal of Controlled Release, 193, 296-303 (2014).

https://doi.org/10.1016/j.jconrel.2014.04.025 
[10] Salalha W., Kuhn J., Dror Y., Zussman E.: Encapsulation of bacteria and viruses in electrospun nanofibres. Nanotechnology, 17, 4675-4681 (2006). https://doi.org/10.1088/0957-4484/17/18/025

[11] Sanders E. H., Kloefkorn R., Bowlin G. L., Simpson D. G., Wnek G. E.: Two-phase electrospinning from a single electrified jet: Microencapsulation of aqueous reservoirs in poly(ethylene-co-vinyl acetate) fibers. Macromolecules, 11, 3803-3805 (2003).

https://doi.org/10.1021/ma0217711

[12] Angkawinitwong U., Sharma G., Khaw P. T., Brocchini S., Williams G. R.: Solid-state protein formulations. Therapeutic Delivery, 6, 59-82 (2015).

https://doi.org/10.4155/tde.14.98

[13] Emami F., Vatanara A., Park E. J., Na D. H.: Drying technologies for the stability and bioavailability of biopharmaceuticals. Pharmaceutics, 10, 131/1-131/22 (2018). https://doi.org/10.3390/pharmaceutics10030131

[14] Mensink M. A., Frijlink H. W., van der Voort Maarschalk K. V. D., Hinrichs W. L. J.: How sugars protect proteins in the solid state and during drying (review): Mechanisms of stabilization in relation to stress conditions. European Journal of Pharmaceutics and Biopharmaceutics, 114, 288-295 (2017).

https://doi.org/10.1016/j.ejpb.2017.01.024

[15] Grasmeijer N., Stankovic M., de Waard H., Frijlink H. W., Hinrichs W. L. J.: Unraveling protein stabilization mechanisms: Vitrification and water replacement in a glass transition temperature controlled system. Biochimica et Biophysica Acta, 1834, 763-769 (2013). https://doi.org/10.1016/j.bbapap.2013.01.020

[16] Wágner I., Nagy Zs. K., Vass P., Fehér Cs., Barta Zs., Vigh T., Sóti P. L., Harasztos A. H., Pataki H., Balogh A., Verreck G., van Assche I., Marosi Gy.: Stable formulation of protein-type drug in electrospun polymeric fiber followed by tableting and scaling-up experiments. Polymers for Advanced Technologies, 26, 1461-1467 (2015). https://doi.org/10.1002/pat.3569

[17] Chew S. Y., Wen J., Yim E. K. F., Leong K. W.: Sustained release of proteins from electrospun biodegradable fibers. Biomacromolecules, 6, 2017-2024 (2005). https://doi.org/10.1021/bm0501149

[18] Sipos E., Szabó Z. I., Rédai E., Szabó P., Sebe I., Zelkó R.: Preparation and characterization of nanofibrous sheets for enhanced oral dissolution of nebivolol hydrochloride. Journal of Pharmaceutical and Biomedical Analysis, 129, 224-228 (2016).

https://doi.org/10.1016/j.jpba.2016.07.004

[19] Persano L., Camposeo A., Tekmen C., Pisignano D.: Industrial upscaling of electrospinning and applications of polymer nanofibers: A review. Macromolecular Materials and Engineering, 298, 504-520 (2013).

https://doi.org/10.1002/mame. 201200290

[20] Theron S. A., Yarin A. L., Zussman E., Kroll E.: Multiple jets in electrospinning: Experiment and modeling. Polymer, 46, 2889-2899 (2005). https://doi.org/10.1016/j.polymer.2005.01.054
[21] Zhou F-L., Gong R-H., Porat I.: Mass production of nanofibre assemblies by electrostatic spinning. Polymer International, 58, 331-342 (2009). https://doi.org/10.1002/pi.2521

[22] Yu M., Dong R-H., Yan X., Yu G-F., You M-H., Ning $\mathrm{X}$., Long Y-Z.: Recent advances in needleless electrospinning of ultrathin fibers: From academia to industrial production. Macromolecular Materials and Engineering, 302, 1700002/1-1700002/19 (2017).

https://doi.org/10.1002/mame.201700002

[23] Nagy Zs. K., Balogh A., Démuth B., Pataki H., Vigh T., Szabó B., Molnár K., Schmidt B. T., Horák P., Marosi Gy., Verreck G., van Assche I., Brewster M. E.: High speed electrospinning for scaled-up production of amorphous solid dispersion of itraconazole. International Journal of Pharmaceutics, 480, 137-142 (2015). https://doi.org/10.1016/j.ijpharm.2015.01.025

[24] Démuth B., Nagy Zs. K., Balogh A., Vigh T., Marosi Gy., Verreck G., van Assche I., Brewster M. E.: Downstream processing of polymer-based amorphous solid dispersions to generate tablet formulations. International Journal of Pharmaceutics, 486, 268-286 (2015).

https://doi.org/10.1016/j.ijpharm.2015.03.053

[25] Szabó E., Démuth B., Nagy B., Molnár K., Farkas A., Szabó B., Balogh A., Hirsch E., Nagy B., Marosi Gy., Nagy Zs. K.: Scaled-up preparation of drug-loaded electrospun polymer fibres and investigation of their continuous processing to tablet form. Express Polymer Letters, 12, 436-451 (2018).

https://doi.org/10.3144/expresspolymlett.2018.37

[26] Blasi P., D’Souza S. S., Selmin F., DeLuca P. P.: Plasticizing effect of water on poly(lactide-co-glycolide). Journal of Controlled Release, 108, 1-9 (2005). https://doi.org/10.1016/j.jconrel.2005.07.009

[27] Breen E. D., Curley J. G., Overcashier D. E., Hsu C. C., Shire S. J.: Effect of moisture on the stability of a lyophilized humanized monoclonal antibody formulation. Pharmaceutical Research, 18, 1345-1353 (2001). https://doi.org/10.1023/A:1013054431517

[28] Kaialy W., Khan U., Mawlud S.: Influence of mannitol concentration on the physicochemical, mechanical and pharmaceutical properties of lyophilised mannitol. International Journal of Pharmaceutics, 510, 73-85 (2016). https://doi.org/10.1016/j.ijpharm.2016.05.052

[29] Nagy Zs. K., Wagner I., Suhajda Á., Tobak T., Harasztos A. H., Vigh T., Sóti P. L., Pataki H., Molnár K., Marosi Gy.: Nanofibrous solid dosage form of living bacteria prepared by electrospinning. Express Polymer Letters, 8, 352-361 (2014). https://doi.org/10.3144/expresspolymlett.2014.39

[30] Zeng J., Aigner A., Czubayko F., Kissel T., Wendorff J. H., Greiner A.: Poly(vinyl alcohol) nanofibers by electrospinning as a protein delivery system and the retardation of enzyme release by additional polymer coatings. Biomacromolecules, 6, 1484-1488 (2005). https://doi.org/10.1021/bm0492576 
[31] Vajdai A., Szabó B., Süvegh K., Zelkó R., Újhelyi G.: Tracking of the viability of Stenotrophomonas maltophilia bacteria population in polyvinylalcohol nanofiber webs by positron annihilation lifetime spectroscopy. International Journal of Pharmaceutics, 429, 135 137 (2012).

https://doi.org/10.1016/j.ijpharm.2012.03.018

[32] Stubbe B., Li Y., Vergaelen M., van Vlierberghe S., Dubruel P., de Clerck K., Hoogenboom R.: Aqueous electrospinning of poly(2-ethyl-2-oxazoline): Mapping the parameter space. European Polymer Journal, 88, 724-732 (2017).

https://doi.org/10.1016/j.eurpolymj.2016.09.014

[33] Briscoe B., Luckham P., Zhu S.: The effects of hydrogen bonding upon the viscosity of aqueous poly(vinyl alcohol) solutions. Polymer, 41, 3851-3860 (2000). https://doi.org/10.1016/S0032-3861(99)00550-9

[34] Tao J., Shivkumar S.: Molecular weight dependent structural regimes during the electrospinning of PVA. Materials Letters, 61, 2325-2328 (2007). https://doi.org/10.1016/j.matlet.2006.09.004

[35] Nagy Zs. K., Nyúl K., Wagner I., Molnár K., Marosi Gy.: Electrospun water soluble polymer mat for ultrafast release of Donepezil HCl. Express Polymer Letters, 4, 763-772 (2010).

https://doi.org/10.3144/expresspolymlett.2010.92
[36] Balogh A., Farkas B., Verreck G., Mensch J., Borbás E., Nagy B., Marosi Gy., Nagy Zs. K.: AC and DC electrospinning of hydroxypropylmethylcellulose with polyethylene oxides as secondary polymer for improved drug dissolution. International Journal of Pharmaceutics, 505, 159-166 (2016).

https://doi.org/10.1016/j.ijpharm.2016.03.024

[37] Borbás E., Balogh A., Bocz K., Müller J., Kiserdei É., Vigh T., Sinkó B., Marosi A., Halász A., Dohányos Z., Szente L., Balogh G. T., Nagy Zs. K.: In vitro dissolution-permeation evaluation of an electrospun cyclodextrin-based formulation of aripiprazole using $\mu$ Flux $^{\mathrm{TM}}$. International Journal of Pharmaceutics, 491, 180-189 (2015).

https://doi.org/10.1016/j.ijpharm.2015.06.019

[38] Hancock B. B., Shamblin S. L.: Water vapour sorption by pharmaceutical sugars. Pharmaceutical Science and Technology Today, 1, 345-351 (1998).

https://doi.org/10.1016/S1461-5347(98)00088-1

[39] Szakonyi G., Zelkó R.: The effect of water on the solid state characteristics of pharmaceutical excipients: Molecular mechanisms, measurement techniques, and quality aspects of final dosage form. International Journal of Pharmaceutical Investigation, 2, 18-25 (2012). https://doi.org/10.4103/2230-973X.96922 